\title{
Association of specific diplotypes defined by common rs1800682 and rare rs34995925 single nucleotide polymorphisms within the STAT1 transcription binding site of the FAS gene promoter with preeclampsia
}

\author{
Zora Lasabova ${ }^{1},{\text { Imrich } Z_{i g o}^{2} \text {, Iveta Svecova }}^{2}$, Gabor Szabo $^{3}$, Andrea Stanclova ${ }^{4}$, Maria $^{2}$ \\ Skerenova ${ }^{5}$, Pavol Zubor ${ }^{2}$, Kristina Biskupska-Bodova2 ${ }^{2}$ Janos Rigo ${ }^{3}$, Balint Nagy $^{3}$ and Jan Danko ${ }^{2}$ \\ ${ }^{1}$ Institute of Molecular Biology, Jessenius Faculty of Medicine in Martin, Comenius University in Bratislava, Slovak Republic \\ ${ }^{2}$ Clinic of Gynecology and Obstetrics, Jessenius Faculty of Medicine in Martin, Comenius University in Bratislava, Slovak Republic \\ ${ }^{3} 1^{\text {st }}$ Department of Obstetrics and Gynaecology, Faculty of Medicine, Semmelweis University, Budapest, Hungary \\ ${ }^{4}$ Department of Pathological Anatomy, Jessenius Faculty of Medicine in Martin, Comenius University in Bratislava, Slovak \\ Republic \\ ${ }^{5}$ Department of Clinical Biochemistry, Jessenius Faculty of Medicine in Martin, Comenius University in Bratislava, Slovak \\ Republic
}

\begin{abstract}
The tolerance of fetal antigens by intradecidual T-cell involving the Fas-mediated apoptosis plays an important role in the physiological course of pregnancy. Objective of this study is to determine the association of diplotypes of common $\mathrm{rs} 1800682^{\mathrm{G}}$ and rare $\mathrm{rs} 34995925^{\mathrm{C}}$ alleles within the STAT1 transcription binding site of the FAS promoter region with preeclampsia. There were 116 preeclamptic women and 123 healthy control subjects from Hungary and Slovakia enrolled in the study. The presence of the GG or GA genotypes on rs1800682 was confirmed in 91 patients and 85 controls $(\mathrm{OR}=1.628,95 \% \mathrm{CI} 0.907-2.92)$. The rare $\mathrm{rs} 34995925^{\mathrm{C}}$ allele laying $7 \mathrm{bp}$ further from rs 1800682 within STAT1 transcription binding site was detected in 3 preeclamptic cases and none healthy subjects. Haplotypes GT and AC were defined by common $\mathrm{rs} 1800682^{\mathrm{G}}$ and rare rs34995925 ${ }^{C}$ alleles, respectively, and were considered as "low" FAS-producing. The combinations of GT or AC with normal FAS-producing haplotypes AT were considered as "low" FAS-producing diplotypes in dominant model. The "low" FAS-producing diplotype group of GT/GT, GT/AT, and AC/AT compared to the normal FAS-producing diplotype group of AT/AT showed OR $=1.91(95 \%$ CI 1.04-3.48) and $p=0.03$ for the association with preeclampsia.
\end{abstract}

Key words: Preeclampsia - FAS promoter region - Diplotypes

\section{Introduction}

Preeclampsia is a multisystem disorder with partial genetic and immunological etiology. The precise role of genetic factors in the development of preeclampsia is unclear, however, the risk of preeclampsia is 2-fold to 5-fold higher in pregnant women with maternal history of this disorder (Noris et al. 2005; Uzan et al. 2011). In a normal pregnancy,

Correspondence to: Zora Lasabová, Institute of Molecular Biology, Jessenius Faculty of Medicine, Comenius University, Malá hora 4A, 03601 Martin, Slovak Republic

E-mail: lasabova@jfmed.uniba.sk extravillous trophoblast from the fetal placenta invades the maternal decidua and transforms maternal spiral arteries. In preeclampsia, the extravillous trophoblast remodeling is incomplete leading to a decrease in placental blood flow, which causes increased blood pressure of the mother and preeclampsia. The presence of placenta is required for the development of the disorder (Roberts and Hubel 2009; van Dijk and Oudejans 2011).

The mechanism of Fas-mediated apoptosis is believed to be involved in the removal of the autoreactive lymphocytes during normal development of immune system. Mutations leading to the reduction or loss of function were shown to be involved into autoimmune diseases (Rieux-Laucat et al. 
1995). The intradecidual T lymphocytes lack immunohistochemically detectable amounts of T-cell receptor molecules that enable placental trophoblast to induce Fas-mediated cell death of T-cells recognizing fetal antigens what results in tolerance of fetal antigens by intradecidual T-cells (Neale and Mor 2005; Stoneman and Bennett 2009).

The role of FAS gene polymorphism rs1800682 (NM 00043.4:c. $-671 \mathrm{~A}>\mathrm{G}$, former $-670 \mathrm{~A}>\mathrm{G}$ ) in preeclampsia is controversial. Previous reports have shown the association of rs1800682 with preeclampsia on Hungarian and Italian cohorts with 38 and 50 preeclamptic patients, respectively (Sziller et al. 2005; Ciarmela et al. 2010). They assumed that maternal possession of $G$ allele increases the risk for preeclampsia because having influence on gene expression. Others have shown the association of the $\mathrm{rs} 1800682^{\mathrm{G}}$ allele with intrauterine growth restriction (Robinson et al. 2009). However, recent findings do not support the role of this polymorphism in the pathogenesis of preeclampsia (Polavarapu et al. 2013).

The changes in the gene expression of genes in this pathway can influence the balance in signaling (Kanemitsu et al. 2002). One of the mechanisms of genetically determined changes in gene expression is based on functional single nucleotide polymorphisms (SNPs) within the promoter region of genes. The polymorphic locus rs 1800682 is located in the enhancer region within a consensus sequence for transcription factor signal transducer and activator of transcription STAT1. Using the electrophoretic mobility shift assay, STAT1 binding activity was found to be higher in $\mathrm{rs} 1800682^{\mathrm{A}}$ allele of the FAS promoter as compared with $\mathrm{rs} 1800682^{\mathrm{G}}$ allele (Kanemitsu et al. 2002). One would expect that the $G$ allele is associated with decreased gene expression leading to reduced apoptosis of intradecidual T-cells whose are then not completely destroyed in FasL-Fas pathway (Ciarmela et al. 2010).

The rs1800682 is a common SNP with MAF $=0.403$ in Caucasian populations (The International HapMap Consortium, 2007). The rare rs34995925 is laying $7 \mathrm{bp}$ further from rs1800682 upstream of the FAS gene transcriptional start and within the STAT1 transcription binding site (Stepanova et al. 2006) with the MAF $<0.05$ according NCBI bdSNP (Sherry et al. 2001). Therefore, the rare $r s 34995925^{C}$ allele might have similar effect of the FAS gene expression as the $\mathrm{rs} 1800682^{\mathrm{G}}$ allele. Based on haplotype and diplotype analysis, we analyzed the additional effect of rs34995925 $\mathrm{C}$ allele on the association with preeclampsia.

\section{Methods}

\section{Patients}

The study is a part of the research carried out in the Centre of Excellence in Perinatology Research and was approved by the Ethical committee of Jessenius Faculty of Medicine. The patients and controls signed an informed consent before entering the study. The study cohort from the Department of Obstetrics and Gynecology in Martin, Slovakia, consists of 46 patients with the diagnosis of preeclampsia and 45 women with physiological course of pregnancy without previous history of preeclampsia or hypertensive disorder. From the Department of Obstetrics and Gynecology of the Semmelweis University in Budapest, Hungary, we included 70 patients with preeclampsia and 78 control subjects. The diagnostic criteria for preeclampsia were identical within both cohorts. The women were classified according to the clinical guidelines for assessment of hypertension disorders in pregnancy, using the Report of the national High Blood Pressure Education Program Working Group on High Blood Pressure in Pregnancy (National High Blood Pressure Education Program Working Group on High Blood Pressure in Pregnancy 2000). The blood pressure of patients was equal to or higher than $140 / 90 \mathrm{mmHg}$ after twentieth week of pregnancy in previously normotensive subjects on two consecutive measurements at least 6 hours apart and proteinuria reached at least $300 \mathrm{mg} / 24 \mathrm{~h}$ in women with no history of proteinuria at baseline. The control subjects had no signs of obstetric or systemic disease and normal physiological course of pregnancy. Exclusion criteria were multiple gestations, diabetes including gestational diabetes, previous cardiovascular diseases, renal disease, autoimmune disease, liver disease, hypertension before $20^{\text {th }}$ week of pregnancy, pre-existing hypertension or proteinuria, pregnancy-induced hypertension, fetal disorder prior to labor onset, in-vitro fertilization, infection, placental abruption and HELLP syndrome. Patients with history of hydatiforme mole in previous pregnancy were excluded from the study.

\section{DNA Extraction}

Genomic DNA was extracted from $100 \mu$ of peripheral blood with EDTA using DNeasy Blood and Tissue DNA Isolation Kit (Qiagen, Germany) according the manufacturer's instructions. Briefly, proteinase $\mathrm{K}$ and lyses buffer were added to $100 \mu \mathrm{l}$ of peripheral blood and the samples were incubated at $56^{\circ} \mathrm{C}$ for $10 \mathrm{~min}$. After addition of ethanol and vortexing, the samples were purified using silica-membrane column and eluted into $100 \mu \mathrm{l}$ of elution buffer. The concentration was estimated by spectrophotometry at $260 \mathrm{~nm}$.

\section{Dideoxysequencing}

PCR for sequencing was preformed with $100 \mathrm{ng}$ extracted DNA in a final volume of $20 \mu \mathrm{l}$ using FastStart Taq polymerase (Roche, Switzerland) with $1.5 \mathrm{mM} \mathrm{Mg}^{2+}$ concentration. The PCR conditions were $10 \mathrm{~min} 95^{\circ} \mathrm{C}$ and thirty cycles at $95^{\circ} \mathrm{C}$ $30 \mathrm{~s}, 64^{\circ} \mathrm{C} 30 \mathrm{~s}$ and $72^{\circ} \mathrm{C} 30 \mathrm{~s}$. The primers rs $1800682 \mathrm{Fseq}$ 5'GTACAGGAGCCTTGGCTAA TTG3' and rs1800682Rseq 
5 TTAATATAGCTGGGGCTATGCGA were designed from GenBank sequence NG_009089 and the PCR was evaluated by agarose electrophoresis. The PCR products were purified with NucleoSpin Extract II kit (Machery-Nagel, UK) and the sequencing reaction was performed using BigDye Terminator kit v1.1 (Applied Biosystems, USA) at $95^{\circ} \mathrm{C} 2 \mathrm{~min}$ and 35 times at $95^{\circ} \mathrm{C} 15 \mathrm{~min}, 60^{\circ} \mathrm{C} 4 \mathrm{~min}$. The fragments were separated on automatic genetic analyzer AB3500 and subsequently evaluated with DNA Sequencing Analysis Software v5.4 and Seqscape v2.7 (Applied Biosystems, USA).

\section{Statistical evaluation}

Goodness of fit to Hardy-Weinberg equilibrium was calculated by comparing the observed genotypes frequencies with the expected values using the chi-square test. For all patient's cohort, the odds ratios (OR) and 95\% confidence intervals (95\%CI) were calculated. The association was determined by two sided Fisher's exact test, $p<0.05$ was considered as significant. Haplotypes were estimated using an expectation- maximization (EM) method (parameters: maximum EM iteration $=50$, EM convergence tolerance $=0.0001)$. Analysis was performed using SNP \& Variation Suite v7.7.3 (Golden Helix, Inc., Bozeman, USA). For haplotypes, the OR and 95\%CI were calculated. For diplotypes, the dominant model was applied (Lunetta 2008) and the OR and 95\%CI determined.

\section{Results}

The rs 1800682 polymorphism in Slovak, Hungarian and united cohorts

The determined genotypes in both, patients and control cohorts of Slovakian and Hungarian patients as well as of united cohort fit the Hardy-Weinberg equilibrium. Of the 239 singleton pregnancies enrolled into study, 116 had preeclampsia while 123 were physiological pregnancies. There were determined 119 (51.3\%) G and $113(48.7 \%)$ A alleles at the rs1800682 locus. Compared to $114 \mathrm{G}$ alleles

Table 1. Results of FAS gene polymorphisms rs1800682 analysis in united Slovak and Hungarian cohorts, in Slovak patients only and Hungarian patients only

\begin{tabular}{|c|c|c|c|c|}
\hline \multicolumn{5}{|c|}{ United Slovak and Hungarian cohorts } \\
\hline Genotype & $\begin{array}{l}\text { Preeclamptic patients } \\
\qquad(n=116)\end{array}$ & $\begin{array}{l}\text { Physiological pregnancies } \\
\qquad(n=123)\end{array}$ & OR $(95 \% \mathrm{CI})$ & $p$ \\
\hline G & $119(51.3 \%)$ & $114(46.3 \%)$ & ${ }^{\mathrm{a}} 1.22(0.85-1.74)$ & 0.314 \\
\hline A & $113(48.7 \%)$ & $132(53.7 \%)$ & - & - \\
\hline GG & $28(24.1 \%)$ & $29(23.6 \%)$ & $\mathrm{b} 1.17(0.62-2.19)$ & 0.747 \\
\hline GA & $63(54.3 \%)$ & $56(45.5 \%)$ & ${ }^{c} 1.71(0.92-3.18)$ & 0.119 \\
\hline $\mathrm{AA}$ & $25(21.6 \%)$ & $38(30.9 \%)$ & - & - \\
\hline GG+GA & $91(78.4 \%)$ & $85(69.1 \%)$ & ${ }^{\mathrm{d}} 1.63(0.91-2.92)$ & 0.108 \\
\hline \multicolumn{5}{|c|}{ Slovak patients only } \\
\hline Genotype & $\begin{array}{c}\text { Preeclamptic patients } \\
(n=46)\end{array}$ & $\begin{array}{l}\text { Physiological pregnancies } \\
\qquad(n=45)\end{array}$ & OR (95\% CI) & $p$ \\
\hline G & $46(50 \%)$ & $40(44.4 \%)$ & ${ }^{\mathrm{a}} 1.25(0.70-2.24)$ & 0.462 \\
\hline A & $46(50 \%)$ & $50(55.6 \%)$ & - & - \\
\hline GG & $11(23.9 \%)$ & $10(22.2 \%)$ & $\mathrm{b}_{1.09}(0.38-3.09)$ & 0.87 \\
\hline GA & $24(52.2 \%)$ & $20(44.5 \%)$ & ${ }^{c} 1.63(0.62-4.35)$ & 0.458 \\
\hline $\mathrm{AA}$ & $11(23.9 \%)$ & $15(33.3 \%)$ & - & - \\
\hline $\mathrm{GG}+\mathrm{GA}$ & $35(76.1 \%)$ & $30(66.7 \%)$ & $\mathrm{d}_{1.59}(0.64-3.98)$ & 0.360 \\
\hline \multicolumn{5}{|c|}{ Hungarian patients only } \\
\hline Genotype & $\begin{array}{c}\text { Preeclamptic patients } \\
(n=70)\end{array}$ & $\begin{array}{l}\text { Physiological pregnancies } \\
\qquad(n=78)\end{array}$ & OR $(95 \% \mathrm{CI})$ & $\mathrm{p}$ \\
\hline G & $73(52.1 \%)$ & $74(47.4 \%)$ & ${ }^{\mathrm{a}} 1.2(0.76-1.91)$ & 0.485 \\
\hline A & $67(47.9 \%)$ & $82(52.6 \%)$ & - & - \\
\hline GG & $17(24.3 \%)$ & $19(24.4 \%)$ & $\mathrm{b}_{1.2}(0.55-2.68)$ & 0.689 \\
\hline GA & $39(55.7 \%)$ & $36(46.2 \%)$ & ${ }^{\mathrm{c}} 1.78(0.80-3.98)$ & 0.167 \\
\hline $\mathrm{AA}$ & $14(20 \%)$ & $23(29.4 \%)$ & - & - \\
\hline $\mathrm{GG}+\mathrm{GA}$ & $56(80 \%)$ & $55(70.6 \%)$ & ${ }^{\mathrm{d}} 1.67(0.78-3.58)$ & 0.250 \\
\hline
\end{tabular}

${ }^{\mathrm{a}} \mathrm{G} v s . \mathrm{A} ;{ }^{\mathrm{b}} \mathrm{GA} v s . \mathrm{GG} ;{ }^{\mathrm{c}} \mathrm{GA} v s . \mathrm{AA} ;{ }^{\mathrm{d}} \mathrm{GG}+\mathrm{GA} v s . \mathrm{AA}$. 
(46.3\%) and $132 \mathrm{~A}$ allels (53.7\%) of the control group, the difference was not statistically significant (Table 1). The GG and GA genotype in preeclamptic cohort of 116 women was detected in 91 cases (78.4\%) and in 85 (69.1\%) subjects from the control group of 123 women (Table 1). However, the observed odds ratio represents 1.628 (95\% CI 0.907 to 2.92), the $p$-value determined by Fisher's exact test is not significant $(p=0.108)$. Once the cohorts were analyzed separately, no significant differences in frequencies were determined $(p>$ 0.05). In the Slovak cohort with preeclampsia, 35 (76.1\%) from 46 patients were carriers of the GG or GA genotypes. In the control group, there were 30 (66.7\%) from 45 (Table 1). The observed OR is 1.59 (95\% CI 0.64 to 3.98$)$ and $p=0.36$. In the Hungarian preeclamptic cohort, $56(80 \%)$ of 70 had GG or GA genotypes. In the control group, there were 55 (70.6\%) of 78 (Table 1). The observed OR is 1.67 (95\% CI 0.78 to 3.58$)$ and $p=0.25$.

\section{Analysis of the rs34995925, haplotypes and diplotypes}

In addition to rs1800682 analysis, we were able to detect the rare variant of $\mathrm{rs} 3499592^{\mathrm{C}}$ laying $7 \mathrm{bp}$ further from the rs1800682 in two patients with preeclampsia in the Slovak cohort; this gives the frequency of heterozygosity 0.04 in the Slovak preeclamptic cohort. This allele was present in one Hungarian preeclamptic woman. In the united cohort, the frequency of heterozygosity amounts to 0.03 .

Estimating haplotypes, we determined frequencies of three different haplotypes within this short promoter region defined by rs 1800682 and rs34995925 (in this order) GT, AT, and AC (Table 2). The rs $1800682^{\mathrm{G}}$ allele of GT haplotype is thought to restrain the FAS gene expression and is localized within the transcription binding site of STAT1; similarly the rs $34995925^{C}$ allele of the AC haplotype. Both, GT and AC have been considered as "low" FAS-producing haplotypes. The AT haplotype have been suggested as normal FAS-producing haplotypes. The OR values showed in Table 2 were calculated using haplotype GT against a sum of all others. Statistical evaluation of odds ratio showed increased incidence of preeclampsia for GT haplotype with

Table 2. Association of the most frequent haplotypes with preeclampsia estimated from rs1800682 and rs34995925 (in this order)

\begin{tabular}{lcc}
\hline Haplotype & $\begin{array}{c}\text { Preeclamptic } \\
\text { pacients (\%) }\end{array}$ & $\begin{array}{c}\text { Physiological } \\
\text { pregnancies (\%) }\end{array}$ \\
\hline GT & $119(51.3)$ & $114(46.3)$ \\
AT & $110(46.8)$ & $133(53.7)$ \\
AC & $3(1.3)$ & 0 \\
\hline
\end{tabular}

$p=0.221$ GT vs. AT; Chi-Squared $\mathrm{X}^{2}=1.501 ; \mathrm{OR}=1.253 ; 95 \%$ $\mathrm{CI}=0.873-1.796$.
Table 3. Statistical evaluation of the "low” and normal FAS-producing diplotypes in dominant model in preeclamptic patients and control subjects in united Slovak and Hungarian cohorts

\begin{tabular}{|c|c|c|c|}
\hline & & $\begin{array}{c}\text { Preeclamptic } \\
\text { patients } \\
(n=116)\end{array}$ & $\begin{array}{l}\text { Physiological } \\
\text { pregnancies } \\
\quad(n=123)\end{array}$ \\
\hline \multirow{4}{*}{$\begin{array}{l}\text { "low“ FAS-producing } \\
\text { diplotypes }\end{array}$} & GT/GT & $28(24.1 \%)$ & $29(23.6 \%)$ \\
\hline & GT/AT & $63(54.4 \%)$ & $56(45.6 \%)$ \\
\hline & $\mathrm{AC} / \mathrm{AT}$ & $3(3.6 \%)$ & 0 \\
\hline & total & $94(81 \%)$ & $85(69 \%)$ \\
\hline \multirow[t]{2}{*}{$\begin{array}{l}\text { normal FAS-producing } \\
\text { diplotypes }\end{array}$} & $\mathrm{AT} / \mathrm{AT}$ & $22(19 \%)$ & $38(31 \%)$ \\
\hline & total & $22(19 \%)$ & 38 (31\%) \\
\hline
\end{tabular}

$\mathrm{OR}=1.253$ (95\%CI 0.873 to 1.796$)$, however, the $p$-value was not significant $(p=0.221)$.

When the dominant model in diplotype analysis was applied, we obtained diplotype group of "low" FAS-producing diplotypes consisting of GT/GT, GT/AT, AC/AT and diplotype AT/AT consisting of normal FAS-producing haplotypes. In the preeclamptic cohort, we determined 94 "low" and 22 normal FAS-producing diplotypes. The control group consists of 85 "low" and 38 normal FAS-producing diplotypes (Table 3). The statistical evaluation showed OR $=1.91$ (95\% CI 1.04 to 3.48 ) and the $p$-value 0.03 is considered as significant.

\section{Discussion}

The role of rs1800682 in the association with preeclampsia is recently controversial. The published reports showed significant association of $\mathrm{G}$ allele with development of preeclampsia in Hungarian population (Sziller et al. 2005) as well as the association of genotypes GG and GA with preeclampsia in dominant manner in Italian population (Ciarmela et al. 2010). The Italian authors Ciarmela et al. considered that the Italian and Hungarian populations are different. When we compared the results concerning frequencies of rs 1800682A $>\mathrm{G}$ in Slovak and Hungarian cohorts, we were not able to determine significant differences between these two groups of patients and controls. Patients and control cohorts of Slovak and Hungarian patients as well as of united cohort fit the Hardy-Weinberg equilibrium. Therefore, we decided to perform the evaluations of analysis in united cohort. Our results focusing on rs1800682 in Slovak and Hungarian cohorts as well as within the united cohort and recent report from an US group did not confirm the association of rs1800682 with the pathogenesis of preeclampsia 
(Polavarapu et al. 2013). However, the reports publishing the results of the rs 1800682 association with preeclampsia are dealing with relative small cohorts between 22 and 50 of patients (Sziller et al. 2006; Ciarmela et al. 2010; Polavarapu et al. 2013) what is one of the main reasons for controversies in SNP association studies. Statistical analyses of such cohorts could contain different statistical errors due to e.g. the number of tested subjects and SNP frequencies. Our united cohort with 116 patients and 123 controls represents the largest one analyzed on FAS gene promoter region in preeclampsia. Some studies suggest that preeclampsia is a multifactorial and multisystemic disease and this fact may influence results of this kind of study (Vatten and Skjaeven 2004; Sziller et al. 2005) accordingly we used criteria based on the Report of the National High Blood Pressure Education program Working Group (National High Blood Pressure Education Program Working Group on High Blood Pressure in Pregnancy 2000). The other problem might be the failure of rare variants identification (Cirulli and Goldstein 2010). In concordance with the common-disease common-variant hypothesis, the most association studies have been focusing on the identification of common alleles with frequencies more than 0.05 . However, most of these associated variants have very small effect on the heredity so the attention is shifted to the searching for rare variants with large effects. The third group of variants is represented by rare variants of small effect which are very hard to identify (Manolio et al. 2009).

Therefore, the combination of both common and rare variants can be necessary to obtain more significant results (Sykes et al. 2011). While the statistical methods for such types of analyses are in development (Aschard et al. 2011) and are focusing on the genome-wide analyses, for our evaluation, we decided to use an approach combining haplotypes with similar effects on the FAS gene expression (EdwardsSmith et al. 1999) in dominant model (Lunetta 2008) and standard statistical evaluation.

Using this approach, we divided the diplotypes into two groups - the "low" FAS-producing diplotypes AT/GT, GT/GT and AT/AC and normal FAS-producing diplotype AT/AT. In preeclampsia, we had 94 cases of "low" and 22 cases of normal FAS-producing diplotypes (Table 3). From 94 cases with "low" FAS-producing diplotypes, 91 are represented by the common $\mathrm{G}$ allele of rs 1800682 and 3 by rare $\mathrm{C}$ allele of rs34995925. We found data concerning the frequency of heterozygosity of rs34995925 in NCBI dbSNP where the declared value was 0.01 by SNP500 Cancer database obtained by sequencing (Packer et al. 2006). However, the frequency in our cohort amounts for 0.03 ; to obtain more accurate results, more patient's samples have to be analyzed in the case of rare SNPs.

One of the mechanisms of genetically determined changes in gene expression is based on functional SNPs within the promoter region of genes. The rs 1800682 within the FAS promoter region is located in the enhancer region and abolishes the binding site of gamma-interferon activating site GAS ATTCCAGG/AAA, where transcription factor signal transducer and activator of transcription STAT1 binds (Huang et al. 1997). Using the electrophoretic mobility shift assay, it was demonstrated that STAT1 binding activity was found to be higher in $\mathrm{rs} 1800682^{\mathrm{A}}$ allele of the FAS promoter as compared with $\mathrm{rs} 1800682^{\mathrm{G}}$ allele (Kanemitsu et al. 2002). We included therefore the AT/GT and GT/GT into the group of "low" FAS-producing haplotypes in the dominant model. Under normal circumstances, FasL secreted by trophoblast is able to induce T-cell death by apoptosis through activation of Fas pathway (Abrahams et al. 2004). The changes in the FAS gene expression can influence the balance in apoptosis signaling and a lower expression of FAS receptor (CD95) was observed on T-cells in preeclamptic women compared to the healthy pregnant controls (Miko et al. 2009). Due to the fact that rs34995925 is laying 7 bp further from rs800682 within the STAT1 TBS site, we suggest, that this SNP has influence on the FAS gene expression. For that reason, we included the AC haplotype with $\mathrm{rs} 1800682^{\mathrm{A}}$ and $\mathrm{rs} 34995925^{\mathrm{C}}$ alleles into the "low" FAS- producing haplotype group and obtained a significant association of the sum of "low" FAS-producing diplotypes compared to the sum of all normal FAS-producing diplotypes with preeclampsia (Table 3 ). Although, there are no functional studies showing the functionality of rs34995925, its importance is underlined by the fact, that we determined the minor allele in 3 preeclamptic patients and in none control subjects.

The data obtained in this study may represent first report of combined analysis of common and rare FAS gene promoter variants influencing the FAS gene expression. Because of the controversial results of different studies, it will be necessary to develop an allele-specific gene expression assay for the validation of the functionality of both SNPs in the T- cells and inclusion of larger cohorts for the SNP analyses.

Acknowledgments. This study was supported by Centre of Excellence in Perinatology Research (IMTS 26220120016) and Grant VEGA 1/0333/12.

Conflict of interest statement. The authors declare that there are no conflicts of interest.

\section{References}

Abrahams W. M., Straszewski-Chavez S. L., Guller S., Mor G. (2004): First trimester trophoblast cells secrete Fas ligand which induces immune cell apoptosis. Mol. Hum. Reprod. 10, 55-63

http://dx.doi.org/10.1093/molehr/gah006 
Aschard H., Qiu W., Pasaniuc B., Zaitlen N., Cho M. H., Carey V. (2011): Combining effects from rare and common genetic variants in an exome-wide association study of sequence data. BMC Proceedings 5 (Suppl 9), 544-546

Ciarmela P., Boschi S., Bloise E., Marozio L., Benedetto C., Castellucci M., Petraglia F. (2010): Polymorphisms of FAS and FAS ligand genes in preeclamptic women. Eur. J. Obstet. Gynecol. Reprod. Biol. 148, 144-146 http://dx.doi.org/10.1016/j.ejogrb.2009.10.026

Cirulli E. T., Goldstein D. B. (2010): Uncovering the role of rare variants in common disease through whole-genome sequencing. Nat. Rev. Genet. 11, 415-425 http://dx.doi.org/10.1038/nrg2779

Edwards-Smith C. J., Jonsson J. R., Purdie D. M., Bansal A., Shorthouse C., Powell E. E. (1999): Interleukin-10 promoter polymorphism predicts initial response of chronic hepatitis $\mathrm{C}$ to interferon alfa. Hepatology 30, 526-530 http://dx.doi.org/10.1002/hep.510300207

Huang Q. R., Morris D., Manolios N. (1997): Identification and characterization of polymorphism in the promoter region of the human Apo-1/FAS (CD95) gene. Mol. Immunol. 34, 577-582 http://dx.doi.org/10.1016/S0161-5890(97)00081-3

Kanemitsu S., Ihara K., Saifddin A., Otsuka T., Takeuchi T., Nagayama J., Kuwano M., Hara T. (2002): A functional polymorphism in Fas (CD95/APO-1) gene promoter associated with systemic lupus erythematosus. J. Rheumatol. 29, 1183-1188

Lunetta K. L. (2008): Genetic association studies. Circulation 118, 96-101 http://dx.doi.org/10.1161/CIRCULATIONAHA.107.700401

Manolio T. A., Collins F. S., Cox N. J, Cox N. J., Goldstein D. B., Hindorff L. A., McCarthy M. I., Ramos E. M., Cardon E. M. et al. (2009): Finding the missing heritability of complex diseases. Nature 461, 747-753

http://dx.doi.org/10.1038/nature08494

Miko E., Szereday L., Barakonyi A., Jarkovich A., Varga P., SzerekesBartho J. (2009): Immunoactivation in preeclampsia: : V $\delta 2+$ and regulatory $\mathrm{T}$ cells during the inflammatory stage of disease. J. Reprod. Immunol. 80, 100-108 http://dx.doi.org/10.1016/j.jri.2009.01.003

National High Blood Pressure Education Program Working Group on High Blood Pressure in Pregnancy (2000): Report of the National High Blood Pressure Education Program Working Group on High Blood Pressure in Pregnancy. Am. J. Obstet. Gynecol. 183, S1-22 http://dx.doi.org/10.1067/mob.2000.107928

Neale D. M., Mor G. (2005): The role of Fas mediated apoptosis in preeclampsia. J. Perinat. Med. 33, 471-477 http://dx.doi.org/10.1515/JPM.2005.085

Noris M., Perico N., Remuzzi G. (2005): Mechanisms of disease: pre-eclampsia. Nat. Clin. Pract. Nephrol. 1, 98-114 http://dx.doi.org/10.1038/ncpneph0035

Packer B. R., Yeager M., Burdett L., Welch R., Beerman M., Qi L., Sicotte H., Staats B., Acharaya M., Crenshaw A., Eckert A., Puri V., Gerhadr D. S., Chanock S. J. (2006): SNP500Cancer: a public resource for sequence validation, assay development, and frequency analysis for genetic variation in candidate genes. Nucleic Acid Res. 34, D617-621 http://dx.doi.org/10.1093/nar/gkj151

Polavarapu S. S., Parton L. A., Maramreddy H., Hsu C.-D. (2013): Are placental Fas and Fas ligand gene polymorphisms associated with preeclampsia? Pregn. Hyperten. Int. J. Women Cardiovasc. Health 3, 34-38 http://dx.doi.org/10.1016/j.preghy.2012.09.003

Rieux-Laucat F., Le Deist F., Hivroz C., Roberts I. A., Debatin K. M., Fischer A., de Villartay J. P. (1995): Mutations in Fas associated with human lymphoproliferative syndrome and autoimmunity. Science 268, 1347-1349 http://dx.doi.org/10.1126/science.7539157

Roberts J. M., Hubel C. A. (2009): The two stage model of preeclampsia: variations on the theme. Placenta 30 (Suppl A), $32-37$ http://dx.doi.org/10.1016/j.placenta.2008.11.009

Robinson R., Hsu C. D., Chesebro A. L., Nguyen J., Ali N., Maramreddy H., Parton L.A. (2009): A single-nucleotide polymorphism (-670) of the maternal Fas gene is associated with intrauterine growth restriction. Am. J. Obstet. Gynecol. 201, 620.e1-4

Sherry S. T., Ward M. H., Kholodov M., Baker J., Phan L., Smigielski E. M., Sirotkin K. (2001): dbSNP: the NCBI database of genetic variation. Nucleic Acid Res. 29, 308-311 http://dx.doi.org/10.1093/nar/29.1.308

Stepanova M., Tiazhelova T., Skoblov M., Baranova A. (2006): Potential regulatory SNPs in promoter of human genes: A Systematic approach. Mol. Cell Probes 20, 348-350 http://dx.doi.org/10.1016/j.mcp.2006.03.007

Stoneman V. E., Bennett M. R. (2009): Role of Fas/Fas-L in vascular cell apoptosis. J. Cardiovasc. Pharmacol. 53, 100-108 http://dx.doi.org/10.1097/FJC.0b013e318198fe60

Sykes J., Cheng L., Xu W., Tsao M.-S., Liu G., Pintille M. (2011): Addition of multiple rare SNPs to known common variants improves the association between disease and gene in the Genetic Analysis Workshop 17 data. BMC Proceedings 5 (Suppl 9), 597-599

Sziller I., Nguyen D., Halmos A., Hupuczi P., Papp Z., Witkin S. S. (2005): An $A>G$ polymorphism at position -670 in the Fas (TNFRSF6) gene in pregnant women with pre-eclampsia and intrauterine growth restriction. Mol. Hum. Reprod. 11, 207-210 http://dx.doi.org/10.1093/molehr/gah151

The International HapMap Consortium (2007): A second generation human haplotype map over 3.1 million SNPs. Nature 449, 851-861 http://dx.doi.org/10.1038/nature06258

Uzan J., Carbonnel M., Piconne O., Asmar R., Ayoubi J.M. (2011): Pre-eclampsia: pathophysiology, diagnosis, and management. Vasc. Health Risk Manag. 7, 467-474

van Dijk M., Oudejans C. B. M. (2011): STOX1: Key Player in trophoblasts dysfunction underlying early onset preeclamspia with growth retardation. J. Pregnancy e521826

Vatten L. J., Skjaeven R. (2004): Is pre-eclampsia more than one disease? Br. J. Obstet. Gynecol. 111, 298-302 http://dx.doi.org/10.1111/j.1471-0528.2004.00071.x

Received: October 15, 2013

Final version accepted: November 11, 2013 